\title{
Narrative review in pediatric and congenital heart surgery in sub- Saharan Africa: challenges and opportunities in a new era
}

\author{
Valdano Manuel $^{1,2} \wedge$, Leonardo A. Miana ${ }^{2} \wedge$, Frank Edwin ${ }^{3,4} \wedge$ \\ ${ }^{1}$ Cardiothoracic Center, Clínica Girassol, Luanda, Angola; ${ }^{2}$ Division of Cardiovascular Surgery, Heart Institute (InCor), Hospital das Clínicas da \\ Faculdade de Medicina da Universidade de São Paulo, São Paulo, Brazil; ${ }^{3}$ School of Medicine, University of Health \& Allied Sciences, Ho, Ghana; \\ ${ }^{4}$ National Cardiothoracic Centre, Korle Bu, Accra, Ghana \\ Contributions: (I) Conception and design: F Edwin, V Manuel; (II) Administrative support: V Manuel; (III) Provision of study materials or patients: \\ All authors; (IV) Collection and assembly of data: All authors; (V) Data analysis and interpretation: All authors; (VI) Manuscript writing: All authors; \\ (VII) Final approval of manuscript: All authors. \\ Correspondence to: Frank Edwin. School of Medicine, University of Health and Allied Sciences, Ho, Ghana. Email: fedwin@uhas.edu.gh.
}

Objective: Describe the dimension of this problem, present the challenges and show opportunities and probable solutions.

Background: Congenital heart disease (CHD) remains a public health problem in developing countries, accounting for a significant portion of child mortality. In sub-Saharan Africa, this situation appears to be worse and requires urgent intervention.

Methods: A narrative overview of the literature was carried out that summarizes the situation of pediatric and congenital heart surgery in sub-Saharan Africa with a focus on challenges and opportunities in this region of the world.

Conclusions: A series of coordinated actions including governmental action (creation of laws and financing infrastructure) supplemented by non-governmental organizations (financial support for training, and education) are highly desirable. The challenges are many and widely described in the literature. However, with the continuous interest of the World Society for Pediatric and Congenital Heart Surgery in Africa and the creation of the African Society for Pediatric and Congenital Heart Surgery, a great opportunity emerges as never before. This will certainly help efforts to improve the care of these children with CHD in one of the poorest regions on the planet.

Keywords: Congenital heart disease (CHD); congenital heart surgery; sub-Saharan Africa; Africa; children

Received: 20 May 2021; Accepted: 21 July 2021; Published: 30 December 2021.

doi: 10.21037/asj-21-34

View this article at: https://dx.doi.org/10.21037/asj-21-34

\section{Introduction}

Congenital heart disease (CHD) was defined by Mitchell (1) as gross structural abnormalities of the heart and intrathoracic great vessels present at birth with actual or potential functional significance. CHD remains a public health problem in developing countries accounting for a significant number of deaths (2-4).

The current population of Africa is close to 1.4 billion people, corresponding to $17.2 \%$ of the world population. Africa's population has an estimated annual growth of $2.5 \%$ with a land area of 29,648,481 $\mathrm{km}^{2}(5)$. The Sahara Desert divides Africa into two distinct regions from a population and economic standpoint, a better developed Northern Africa and sub-Saharan Africa (Figure 1) (6).

Sub-Saharan Africa is made up of 48 countries. The majority of the African population lives in this region with a median age of 19.7 years (5).

^ ORCID: Valdano Manuel, 0000-0001-5740-7707; Leonardo A. Miana, 0000-0001-5806-6780; Frank Edwin, 0000-0001-5174-8017. 


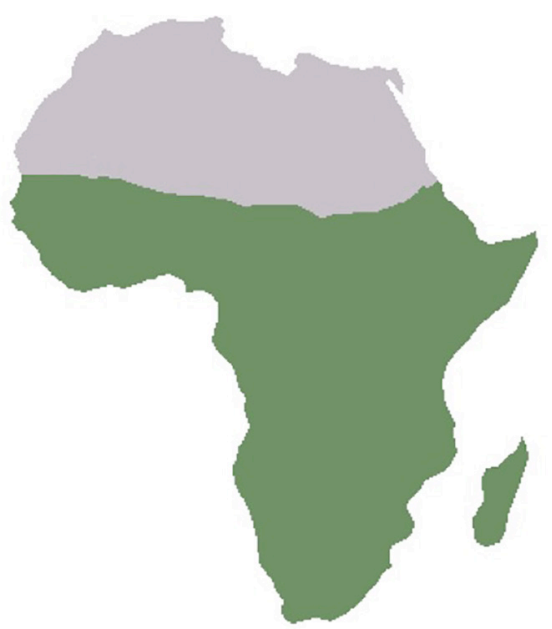

Figure 1 Africa map highlighting the sub-Saharan region (green).

It is widely known that infectious disease is a major burden in sub-Saharan Africa, linked to low basic sanitary conditions. Majority of public health efforts are directed towards infectious disease $(7,8)$.

On the other hand, due to the high fertility rate $(4.44 ; 2020)$, the incidence of CHD is high in this part of the world (9). This high burden of CHD remains largely untreated, and accounts for a significant portion of child mortality, probably as important as infectious disease (2,5,8,10-13).

The prevalence of CHD for sub-Saharan African children varies from 2.2 to 14.4 per 1,000 live births (14-17). CHD contributes to approximately $1 \%$ of deaths per 1,000 live births (17). There is little data available regarding the prevalence of CHD in the adult population of SubSaharan countries. A study including more than 4,000 echocardiogram studies in adult patients observed a prevalence of $2.5 \%$ of CHD in this population (16). In addition, the total annual new caseload of CHD in subSaharan Africa using 2013 country data for extrapolation yields 258,875 CHD cases (mean of 5,393 $\pm 8,625$; median 3,185 ; range, 13-52,814). Six countries (Nigeria, Democratic Republic of the Congo, Ethiopia, Tanzania, Uganda, and Kenya) together accounted for 138,506 , or $53.5 \%$, of the total annual CHD burden in sub-Saharan Africa (18).

Diagnosis and surgical or catheter-based treatment is scarce, and in many cases non-existent $(2,10,19,20)$. There is an urgent need for investment in the care of CHD patients in Sub-Saharan African countries.

The aim of this review is to describe the dimensions of this problem, identify the opportunities and suggest possible ways of addressing the issue. We present the following article in accordance with the Narrative Review reporting checklist (available at https://asj.amegroups.com/article/ view/10.21037/asj-21-34/rc).

\section{Methods}

For this narrative review we used the PubMed database without limited time using the keywords congenital heart disease; CHD; congenital heart surgery; Africa; subSaharan Africa; pediatric congenital heart surgery. We also have used other sources such as personal experience, direct communications, college libraries, and discussions with practitioners in the field.

\section{Discussion}

\section{Healthcare spending and CHD care}

Although communicable diseases are still responsible for $56 \%$ of deaths in sub-Saharan Africa, a reduction in this group of diseases has been observed. On the other hand, an increase in non-communicable diseases (NCD) corresponding to $25 \%$ is currently also registered. Among the NCDs, cardiovascular causes are responsible for nearly half the cases (21).

There are no studies yet that investigate the mortality of repaired or unrepaired CHD in Africa. What is known is the restricted access and the poor survival without treatment. In Ghana for example, access to diagnosis and treatment of CHD within 2 years of birth is less than $1 \%$ (18). The survival pattern of children born with CHD in Africa was evaluated using the experience in Ghana. Unlike what pertains in developed countries, CHD remains a pediatric disease in Africa; adults living with CHD made up just $10 \%$ of 2,464 persons living with CHD in Ghana. This suggests an exaggerated mortality in childhood, particularly in the first five years of life (11).

As previously described, there is a lack of timely CHD diagnosis in Africa $(2,12-18)$. As opposed to developed countries where $90 \%$ of the cases receive a diagnosis before the first year of life (22), most Sub-Saharan African children are diagnosed after the first year of life. For example, the average age at diagnosis in Mozambique was four years old (12). In Angola, 283 children with VSD were diagnosed at a mean age of 29 months (2). In Nigeria, only $33 \%$ of the diagnoses were made before the first year of life (23). These exemplify the sub-Saharan picture in terms of diagnostic 
timing.

Out of the many reasons identified, the lack of an adequate healthcare infrastructure, trained specialists, specialized equipment, inadequate prenatal care, accessibility barriers to existing facilities, pediatric services investments directed towards treating malnutrition and infectious diseases, and lack of political commitment are paramount $(2,7)$.

It is a multifaceted problem, and probably the impact of mitigating one or two of those issues may not impact on CHD care significantly $(2,11,21,24)$. There is a need for a holistic and systematic improvement, beginning with provision of adequately equipped hospitals, professionals (physicians, nurses, respiratory therapists, perfusionists, sonographers), technology, and health education for patients and their families $(4,22,25)$.

Out of the few existing centers in Sub-Saharan Africa, the majority of children cared for are beyond infancy, different from what is observed in developed countries $(2,12,14,26-28)$.

It is well established that late referral is associated with worse outcomes. Sometimes, in sub-Saharan Africa, cases arrive so late that they jeopardize their surgical candidacy (2).

This difficulty cannot be overcome in a short period of time because the majority of these sub-Saharan African countries have very low gross national incomes (GNI) and very low per capita healthcare expenditure. Low per capita healthcare spending by African governments and the necessity to directly finance healthcare out-ofpocket discourage health-seeking behavior in sub-Saharan Africa and contributes to the poor health outcomes in the region. The seminal paper of Newhouse in 1977 showed an inescapable link between GNI per capita and health expenditure per capita (29).

Newhouse demonstrated that among a group of 13 developed countries; GNI per capita explained 92 percent of the variance in per capita health expenditure. Other studies have confirmed that this strong positive relationship remains after accounting for additional factors, such as country-specific demographic characteristics. The Lancet Commission on global surgery showed a direct relationship between total health expenditure per capita and the observed number of operations performed per 100,000 population (30). Increasing GNI per capita was similarly correlated with surgical volumes: a $10 \%$ increase in GNI per capita leads to a $7.6 \%$ increase in surgical volume (31). A parallel observation is that the population density of pediatric cardiac surgeons very closely follows the distribution of GNI (32).

These GNI-related phenomena have very dire implications for sub-Saharan Africa: improved economic performance in sub-Saharan Africa is an important prerequisite for improved pediatric cardiac care. That being noted, other pre-requisites apply also. The creation of a network for intra and interdisciplinary teleconsultation with professionals from developed countries is an affordable option. Besides that, the idea of having a centralized control of all potential CHD patients with referral to specialized centers might improve accessibility.

There are no specific data on GNI and how it is disbursed in African countries. What is known in Africa is that surgical conditions receive little or no priority in the national health plans of African countries. In a systematic review of the national health plans of 43 independent subSaharan African countries, all countries represented had documented plans and measurable targets for the reduction of HIV and tuberculosis.

Of the 4,064 health targets identified in these plans, only $2 \%$ were related to surgical conditions or surgical care (none to CHD); $33 \%$ of the policies had no surgical targets whatsoever (33). Surgical conditions that receive attention are the ones relating to ophthalmic care-trachoma surgery and cataract. So in Africa, communicable disease receives all the attention, CHD is hardly known by policy makers.

\section{Congenital beart surgery centres}

The number of congenital cardiac surgeries performed in this region of Africa is extremely low; it is estimated that only $3 \%$ of needy children can undergo surgery (17). A survey conducted in 2012 showed that in that year 1277 open heart operations were conducted in sub-Saharan Africa excluding the Republic of South Africa, translating into 1.6 open heart operations per million population (26).

The exact number of pediatric cardiovascular surgeons performing congenital heart surgery in Africa is still unknown, but the African Society for Pediatric Congenital Heart Surgery (ASPCHS) is working on a project to gather this data. Using the CTSNet registered surgeons' database, Vervoort and coworkers estimated 0.19 pediatric cardiac surgeons per million population in sub-Saharan Africa (32). As of 2012, sub-Saharan Africa had 265 cardiothoracic surgeons (26). The inclusion of surgeons who perform adult cardiac surgeries in pediatric and congenital cardiac surgery programs with additional and permanent training might help meet the demand for pediatric and congenital heart surgery. 
The number of referral centers for pediatric and congenital heart surgery in Sub-Saharan Africa is small compared to other middle and low-income countries. For example, Brazil in South America has more than 50 pediatric cardiovascular surgery programs founded by the government (3). Excluding South Africa, Sub-Saharan Africa has less than 25 centers. When analyzed per million inhabitants, sub-Saharan Africa has one center per 33.3 million (26).

Before the COVID-19 pandemic, some volunteer teams carried out humanitarian missions in Africa, mainly in Sub-Saharan countries. This initiative has enormous value and helps many children, but that alone does not solve the problem. There is a need to create self-sustained centers; this implies building local teams, providing consumable material, and developing referral centers across entire countries $(2,15,26,34-36)$.

\section{Training and education}

Although the situation demands urgent attention, sustainable and lasting solutions are required. The result of pediatric cardiac surgery is dependent on the intervention of various actors from different areas of expertise; and most of all they have to work together as a team. There is an evident need to train specialists from the entire chain of care. Training for congenital heart surgery in Africa is challenging $(37,38)$. Most countries just manage with a general cardiothoracic surgery-training program.

The best long-term investment is team training. Professionals from different sectors of CHD care, from screening to post-operative follow-up and also Grown-up Congenital Heart (GUCH) specialists (37), needs specific training to work together as a team.

In the same way that there are few centers with pediatric cardiac surgery programs, there are also few training centers and opportunities to train pediatric and congenital heart surgery teams.

Countries such as South Africa, Ghana and Kenya have training programs, but on the other hand there are several countries that do not even have active heart surgery training programs, such as Angola $(20,26)$.

International collaboration with recognized training institutions should be seen as an opportunity in the face of this challenge $(26,37)$. Many centers achieve suboptimal results with complex surgeries (RACHS 4-6) because of inexperience with handling such cases $(22,37)$. Training is the key to success (38).

\section{Infrastructure and quality bealthcare}

In addition to the well-qualified professionals, infrastructure is a key point to provide a high-quality service (18-20,38-43). Private hospitals clearly present better conditions, but public facilities, where most of the patients are treated, have severely impaired infrastructure. The latter depends on government funding and key policy initiatives $(39,40)$.

These healthcare gaps exist because of systemic infrastructural inadequacies in sub-Saharan Africa particularly evident in cardiovascular care. Delivering quality cardiac healthcare to children in such a setting is a formidable task requiring substantial investments in trained staff, equipment, and infrastructure $(11,18)$. However, the simple coexistence of infrastructure, equipment, and trained healthcare providers does not guarantee optimal healthcare. Improvement in health care delivery requires a deliberate focus on quality, which is understood to mean the degree to which health services for individuals and populations increase the likelihood of desired health outcomes and are consistent with current professional knowledge.

This deliberate focus on quality is generally not evident in much of sub-Saharan Africa. Several systemic deficiencies account for this-poor health information systems and outdated models of healthcare financing.

Treating children with CHD requires a family-centered approach as part of quality care. It is important to plan boarding facilities to accommodate families who must travel long distances cross country while seeking care. Such issues are also problematic in sub-Saharan Africa where in many large countries, single center care based in the capital is the only access to pediatric and congenital heart surgery families can expect.

Three different models have been proposed based on already successful centers in Africa: the three models were used for developing cardiac programs in sub-Saharan Africa (27).

In Model 1 (Ghanaian-German, Namibian), a senior local consultant cardiac surgeon with governmental and private foundation funding developed national capacity building programs.

Model 2 has been used in 21 centers. Visiting teams are funded by NGOs and charged with local staff training.

Model 3 is used in Kenya. It is a modification of Model 1 in which in the absence of an indigenous senior local consultant, an expatriate surgeon on contract leads the capacity building effort. 


\section{Research, databases, and philanthropy}

The use of computerized health information systems is grossly limited in Africa; paper-based systems still predominate in sub-Saharan Africa. In countries where electronic systems have been deployed, their use has been driven by the need to report aggregate statistics for government or funding agencies related to HIV/AIDS and other infectious diseases (41). Birth and death registrations are largely paper-based; basic records of newborns at delivery and discharge, data on congenital heart defects, and important ailments such rheumatic heart disease are all paper-based and nearly impossible to retrieve after the first few years elapse. National systems of unique patient identifiers to support quality monitoring across pathways of care are virtually non-existent.

There is a well-known quote by Lord Kelvin that says, "If you can not measure it, you can not improve it". That said, it is crucial that all centers in Sub-Saharan Africa collect their data and join an international database. This could be an independent African database, or they could join already existing initiatives like the World Database for Pediatric Congenital Heart Surgery (WDPCHS) or the International Quality Improvement Collaborative (IQIC) $(18,42)$.

By doing so, African programs will have a benchmark on which to base their quality improvement initiatives.

The role of NGOs working in sub-Saharan Africa in pediatric cardiac care is important. In a survey of 80 NGOs providing pediatric cardiovascular care in low- and middle-income countries, the largest percentage of NGO outreach efforts was in South and Central America (42\%), followed by Africa (18\%), Europe (17\%), Asia (17\%), and the Asia-Western Pacific region (6\%). The majority (87\%) of them provided education, diagnostics, and surgical or catheter-based interventions. Their contribution to the care of patients in these regions is substantial; often they are the only source of pediatric cardiac interventions in the countries they serve (43-46).

\section{Opportunities}

\section{Harnessing outbound medical travel expenditure}

The many accounts of grossly inadequate pediatric cardiac surgical care and its challenges in sub-Saharan Africa are so daunting it is nearly impossible to see opportunities or solutions. Concerning India, Govindarajan and Ramamurti (47) observed in 2013: "India might be the last place on earth where you'd expect to find health care innovation. The nation's ability to meet the basic medical needs of its citizens remains abysmal. Of the 2 million Indians in need of heart surgery, fewer than $5 \%$ get it. Hospital beds are in short supply, and most medical facilities are dated, cramped, and often unhygienic. In a country where the nominal per capita income is only $\$ 1,500$ a year, patients typically have to pay $60 \%$ of health care expenses from their own pockets." This would not be a country you would expect to attract medical tourists, and yet, in the year 2010, an average of 3,000 Nigerians traveled to India for medical purposes each month, spending around USD 200 million for medical care (47-50).

In 2012, India issued 18,000 medical visas to Nigerian patients alone and received USD 260 million as revenue (50).

Sub-Saharan African medical travelers are the largest contributors to the Indian medical travel industry in terms of numbers and revenue $(49,50)$.

In 2016, Africans travelling to Europe, North America, and Asia for medical care spent over $\$ 6$ billion on outbound medical treatment (50).

How is it that the poorest continent is the largest single contributor to outbound medical travel revenue in India and spent over USD 6 billion in outbound healthcare in 2016? What would it mean for children born with CHD in Africa if its countries developed the capacity to absorb all that expenditure within their borders? In short, what is observed is inequality in the distribution of opportunities for the treatment of CHD.

\section{Changing paradigms}

African governments tend to view themselves as custodians of universal healthcare. However, what is obvious is that this political paradigm has failed across many countries in sub-Saharan Africa. Even the Abuja declaration, which had modest targets for healthcare, in general has failed spectacularly. A 2007 award-winning essay proposed it was time to rethink healthcare delivery in sub-Saharan Africa (51). The authors argued that instead of focusing solely on governments as the major financers and providers of health care, the priority should be to complement government efforts by encouraging private-sector initiatives whose goal is "to provide affordable access to high quality health care for low-income households." As old as the essay is, its recommendations seem to parallel the approach followed by the modern giants of quality cardiac care in India (45). The search for innovative care delivery models that lower costs, improve quality, and increase access to services is probably best articulated by India's Narayana Health where the average cost of open- heart surgery is less than $\$ 2,000$. The same 
procedure at a U.S. research hospital typically costs more than $\$ 100,000$. They achieved this by leveraging economies of scale, using assembly line concepts for surgery, reducing the average length of stay, and reengineering the design, materials, and use of medical equipment to reduce the cost of ownership (51).

Schellekens and coworkers (52) recommended the setting up of risk-pooling schemes from existing out-ofpocket payments that will lower costs, raise quality, increase willingness to pay and boost contributed funds. In the context of the multi-billion dollar outbound medical travel expenditure in Africa, such a policy, if adopted, will contribute greatly to both local healthcare and the national economy. The final recommendation is that high-quality standards should be initiated and enforced by the healthcare professionals, not only by the authorities. Weak and unenforceable quality control standards are among the major drivers of outbound medical travel arising from Africa. Sub-Saharan Africa is composed of many countries with different political and socio-cultural environments. Arguably, no two countries in the world are the same.

Yet, lessons and cautions may be drawn from developing countries that have achieved some success in this endeavor. India is home to global leaders in cardiac care such as the Narayana Hospitals acclaimed for providing high-quality cardiovascular surgery at low cost. China boasts of the World's largest cardiovascular science center with more than 1,200 beds providing state-of-the-art patient care and world-class basic and clinical research in the Fuwai Hospital in Beijing $(53,54)$.

\section{Championing appropriate policies}

The successes of these countries suggest three areas need important political commitment and investment in subSaharan Africa一financing, organization, and regulation (55).

Reproducing the successes of India and China will prove challenging in Sub-Saharan Africa and requires champions in the profession to steer the effort. In this light, the recent establishment of ASPCHS is timely. The ASPCHS is the scientific society of pediatric and congenital heart surgeons and allied specialists of Africa. The inception of ASPCHS followed a town hall meeting with a focus on Africa initiated by the WSPCHS in May 2020. The ASPCHS was developed through close collaboration with the WSPCHS with similar goals and objectives. The vision of the ASPCHS is that every child born anywhere in Africa with a CHD should have access to appropriate medical and surgical care. To attain this lofty ambition, the Society has adopted the mission to promote the highest quality comprehensive cardiac care to all patients with pediatric and/or CHD, from the fetus to the adult, regardless of the patient's economic means, with an emphasis on excellence in education, research and community service. The ASPCHS will serve as the professional and advocacy platform to advance political priority for the care of Africa's children and adults living with CHD and promote public-private partnerships to leverage current opportunities to achieve that goal.

Financial model of care: the vast majority of people in sub-Saharan Africa cannot afford and need some financial risk pooling device (insurance) to help obtain service provided at public institutions. The downside with public institutions is often that remuneration of workers is suboptimal, and equipment and consumables may not be available throughout the year. As a result, service downtime compromises delivery and quality. Private providers tend to be more business minded but operate at a relatively higher service delivery price. A small percentage of people may be able to afford privately funded care and therefore private providers should be encouraged to make quality services available - at least those who will travel outside the country can obtain quality care within the country from private providers. Occasionally, philanthropists are happy to sponsor care from an in-country provider rather than send the patient abroad. South Africa has the two systems that work relatively well-better quality and reliability at the private hospitals but those who cannot afford can get service at public hospitals. Retention of professionals is more difficult as the government cannot afford to pay them well. But if governments encourage private providers, then professionals can work in both public and private hospitals and reach a compromise.

Organizational model: where should a center-ofexcellence for CHD be based, pediatric hospital or cardiac center: both adult/children? Most countries without cardiac programs will start with an adult program not a pediatric one-because the funding and personnel requirements are more manageable with an adult program. Pediatric programs should start off within these adults programs until they gain some financial sustainability to stand on their own.

Regulation mode: in sub-Saharan Africa, children's heart hospitals operated by governments are best housed within adult cardiac centers, as funding is always a problem.

The last question is: How will the professionals be retained? 
There is always the risk of losing trained personnel. The better way to retain them is to design a center of excellence with consistent outcomes for the patients. Another alternative is to arrange specific contracts between the professionals and the government, where once the professional is trained using government funds, he becomes obligated to fulfill an amount of time working in public service, similar to what is still in place and happened with one of us (VM) and many other doctors in Angola (56).

\section{Conclusions}

What needs to be done is not in doubt. It is clear however that African governments must prioritize the care of patients with CHD. They must demonstrate a commitment to the care of these patients with substantial investments in infrastructure and manpower development together with appropriate healthcare financing. Most African countries need to establish cardiac centers for CHD also build or improve social infrastructure. That would bring benefits to all stakeholders.

CHD research in Africa has focused more on the technical dimensions of the problem, such as which surgical interventions are most effective, rather than its political dimensions.

But we must recognize that CHD is both a political and technical challenge. Even if we identify the most effective interventions, there is no guarantee that political leaders (the spending officers of the public) will pay any attention. CHD is one among thousands of issues such leaders confront each year, and they have scarce resources to deal with the multitude of problems. CHD will become their priority only if we develop and carry out effective political initiatives to convince these leaders of the worthiness of the cause.

Governments must realize the important potential contribution of the private sector to the growth of the pediatric cardiac healthcare delivery and embark on appropriate public-private partnerships. We favor a health care system in which governments and the private sector work together for the development of world class quality care funded by pre-paid insurance coverage for citizens to access pediatric cardiac care in sub-Saharan Africa.

\section{Acknowledgments}

Funding: None.

\section{Footnote}

Provenance and Peer Review: This article was commissioned by the Guest Editors (Dominique Vervoort and Marcelo Cardarelli) for the series "Addressing Global Disparities in Pediatric and Congenital Cardiac Care" published in $A M E$ Surgical fournal. The article has undergone external peer review.

Reporting Checklist: The authors have completed the Narrative Review reporting checklist. Available at https:// asj.amegroups.com/article/view/10.21037/asj-21-34/rc

Peer Review File: Available at https://asj.amegroups.com/ article/view/10.21037/asj-21-34/prf

Conflicts of Interest: All authors have completed the ICMJE uniform disclosure form (available at https://asj.amegroups. com/article/view/10.21037/asj-21-34/coif). The series "Addressing Global Disparities in Pediatric and Congenital Cardiac Care" was commissioned by the editorial office without any funding or sponsorship. The authors have no other conflicts of interest to declare.

Ethical Statement: The authors are accountable for all aspects of the work in ensuring that questions related to the accuracy or integrity of any part of the work are appropriately investigated and resolved.

Open Access Statement: This is an Open Access article distributed in accordance with the Creative Commons Attribution-NonCommercial-NoDerivs 4.0 International License (CC BY-NC-ND 4.0), which permits the noncommercial replication and distribution of the article with the strict proviso that no changes or edits are made and the original work is properly cited (including links to both the formal publication through the relevant DOI and the license). See: https://creativecommons.org/licenses/by-nc-nd/4.0/.

\section{References}

1. Mitchell SC, Korones SB, Berendes HW. Congenital heart disease in 56,109 births. Incidence and natural history. Circulation 1971;43:323-32.

2. Mocumbi AO, Lameira E, Yaksh A, et al. Challenges on the management of congenital heart disease in developing 
countries. Int J Cardiol 2011;148:285-8.

3. Vervoort D, Meuris B, Meyns B, et al. Global cardiac surgery: Access to cardiac surgical care around the world. J Thorac Cardiovasc Surg 2020;159:987-996.e6.

4. Ansong AK, Yao NA, Fynn-Thompson F, et al. Delivering pediatric cardiac care in sub-Saharan Africa: a model for the developing countries. Curr Opin Cardiol 2021;36:89-94.

5. Worldometer. Africa Population. Accessed 07.08.2021. Available online: https://www.worldometers.info/worldpopulation/africa-population/

6. Bentahar Z. Continental Drift: The Disjunction of North and Sub-Saharan Africa. Research in African Literatures 2011;42:1-13.

7. Gouda HN, Charlson F, Sorsdahl K, et al. Burden of noncommunicable diseases in sub-Saharan Africa, 1990-2017: results from the Global Burden of Disease Study 2017. Lancet Glob Health 2019;7:e1375-87.

8. Okpechi IG, Ameh OI, Bello AK, et al. Epidemiology of Histologically Proven Glomerulonephritis in Africa: A Systematic Review and Meta-Analysis. PLoS One 2016;11:e0152203.

9. Hoffman JI, Kaplan S. The incidence of congenital heart disease. J Am Coll Cardiol 2002;39:1890-900.

10. Vervoort D, Edwin F. Treating pediatric and congenital heart disease abroad? Imperatives for local health system development. Int J Cardiol Congenit Heart Dis. 2021;2:100082.

11. Edwin F, Zühlke L, Farouk H, et al. Status and Challenges of Care in Africa for Adults With Congenital Heart Defects. World J Pediatr Congenit Heart Surg 2017;8:495-501.

12. Manuel V, Morais H, Manuel A, et al. Ventricular septal defect in children and adolescents in Angola: experience of a tertiary center. Rev Port Cardiol 2014;33:637-40.

13. Jivanji SGM, Lubega S, Reel B, et al. Congenital Heart Disease in East Africa. Front Pediatr 2019;7:250.

14. Keates AK, Mocumbi AO, Ntsekhe M, et al. Cardiovascular disease in Africa: epidemiological profile and challenges. Nat Rev Cardiol 2017;14:273-93.

15. Marijon E, Tivane A, Voicu S, et al. Prevalence of congenital heart disease in schoolchildren of sub-Saharan Africa, Mozambique. Int J Cardiol 2006;113:440-1.

16. Ejim E, Anisiuba B, Oguanobi N, et al. Congenital heart diseases in adults: a review of echocardiogram records in enugu, South-East Nigeria. Ann Med Health Sci Res 2014;4:522-5.

17. Zimmerman M, Sable C. Congenital heart disease in low-and-middle-income countries: Focus on subSaharan Africa. Am J Med Genet C Semin Med Genet 2020;184:36-46.

18. Edwin F, Entsua-Mensah K, Sereboe LA, et al. Conotruncal Heart Defect Repair in Sub-Saharan Africa: Remarkable Outcomes Despite Poor Access to Treatment. World J Pediatr Congenit Heart Surg 2016;7:592-9.

19. Ujunwa FA, Ujuanbi IS, Chinawa JM. Complex congenital heart diseases among children presenting for cardiac surgery in a tertiary health facility in Enugu; South-East Nigeria. A rising trend. Niger J Clin Pract 2021;24:100-3.

20. Nunes MAS, Magalhães MP, Uva MS, et al. A multinational and multidisciplinary approach to treat CHD in paediatric age in Angola: initial experience of a medical-surgical centre for children with heart disease in Angola. Cardiol Young 2017;27:1755-63.

21. Dalal S, Beunza JJ, Volmink J, et al. Non-communicable diseases in sub-Saharan Africa: what we know now. Int J Epidemiol 2011;40:885-901.

22. Richmond S, Wren C. Early diagnosis of congenital heart disease. Semin Neonatol 2001;6:27-35.

23. Sani MU, Mukhtar-Yola M, Karaye KM. Spectrum of congenital heart disease in a tropical environment: an echocardiography study. J Natl Med Assoc 2007;99:665-9.

24. Zühlke L, Lawrenson J, Comitis G, et al. Congenital Heart Disease in Low- and Lower-Middle-Income Countries: Current Status and New Opportunities. Curr Cardiol Rep 2019;21:163.

25. Manuel V, Morais H, Turquetto ALR, et al. Single Ventricle Palliation in a Developing Sub-Saharan African Country: What Should be Improved? World J Pediatr Congenit Heart Surg 2019;10:164-70.

26. Kinsley RH, Edwin F, Colsen PR, et al. Paediatric cardiac surgery for a continent-the experience of the Walter Sisulu Paediatric Cardiac Centre for Africa: paediatric cardiac surgery. SA Heart Journal 2011;8:122-9.

27. Yankah C, Fynn-Thompson F, Antunes M, et al. Cardiac surgery capacity in sub-saharan Africa: quo vadis? Thorac Cardiovasc Surg 2014;62:393-401.

28. Hoosen EGM, Cilliers AM, Hugo-Hamman CT, et al. Audit of paediatric cardiac services in South Africa. SA Heart Journal 2010;7:4-9.

29. Hörer J, Hirata Y, Tachimori H, et al. Pediatric Cardiac Surgical Patterns of Practice and Outcomes in Japan and Europe. World J Pediatr Congenit Heart Surg 2021;12:312-9.

30. Newhouse JP. Medical-care expenditure: a cross-national survey. J Hum Resour 1977;12:115-25. 
31. Weiser TG, Haynes AB, Molina G, et al. Estimate of the global volume of surgery in 2012: an assessment supporting improved health outcomes. Lancet 2015;385 Suppl 2:S11.

32. Verguet S, Alkire BC, Bickler SW, et al. Timing and cost of scaling up surgical services in low-income and middleincome countries from 2012 to 2030: a modelling study. Lancet Glob Health 2015;3 Suppl 2:S28-37.

33. Chireshe J, Ocran MK. Health care expenditure and health outcomes in sub-Saharan African countries. Afr Dev Rev 2020;32:349-61.

34. Miana LA, Manuel V, Antoniali F, et al. COVID-19 pandemic implications in paediatric and congenital heart surgery in Brazil. Cardiol Young 2021. [Epub ahead of print]. doi: 10.1017/S1047951121001608.

35. Nwafor IA, Eze JC. Surgical management of CHD in the adult population: the role of humanitarian cardiac surgery mission in Nigeria. Cardiol Young 2019;29:11-5.

36. Woldmichael KG, Aklilu TM. Mission-based cardiac surgery and catheter treatment of coarctation of aorta in the young and older children: a facility based review of cases in Addis Ababa. Pan Afr Med J 2019;34:160.

37. Jacobs JP, Tchervenkov CI, Stellin G, et al. History of the World Society for Pediatric and Congenital Heart Surgery: The First Decade. World J Pediatr Congenit Heart Surg 2018;9:392-406.

38. Tchervenkov CI, Herbst C, Jacobs JP, et al. Current Status of Training and Certification for Congenital Heart Surgery Around the World: Proceedings of the Meetings of the Global Council on Education for Congenital Heart Surgery of the World Society for Pediatric and Congenital Heart Surgery. World J Pediatr Congenit Heart Surg 2021;12:394-405.

39. Edwin F, Tettey M, Aniteye E, et al. The development of cardiac surgery in West Africa--the case of Ghana. Pan Afr Med J 2011;9:15.

40. Pinto Júnior VC, Fraga MN, Freitas SM. Analysis of ordinances regulating the national policy of high complexity cardiovascular care. Rev Bras Cir Cardiovasc 2012;27:463-8.

41. Zühlke L, Mirabel M, Marijon E. Congenital heart disease and rheumatic heart disease in Africa: recent advances and current priorities. Heart 2013;99:1554-61.

42. Kavuma M. The Usability of Electronic Medical Record Systems Implemented in Sub-Saharan Africa: A Literature Review of the Evidence. JMIR Hum Factors 2019;6:e9317.

43. Louis JS, Kirklin J. The World Database for Pediatric and Congenital Heart Surgery: Update. World J Pediatr
Congenit Heart Surg 2018;9:273-5.

44. International Quality Improvement Collaborative. Available online: https://iqic.chboston.org/

45. Children's HeartLink. Available online: https:// childrensheartlink.org/

46. Nguyen N, Jacobs JP, Dearani JA, et al. Survey of nongovernmental organizations providing pediatric cardiovascular care in low- and middle-income countries. World J Pediatr Congenit Heart Surg 2014;5:248-55.

47. Govindarajan V, Ramamurti R. Delivering world-class healthcare, affordably. Harvard Business Review. Online featured article in November 2013 issue. Accessed 18 May 2021. Available online: https://hbr.org/2013/11/deliveringworld-class-health-care-affordably.

48. Khan MJ, Khan F, Amin S, et al. Perceived Risks, Travel Constraints, and Destination Perception: A Study on Sub-Saharan African Medical Travellers. Sustainability 2020;12:2807.

49. Abimbola S. How We Made It in Africa - 15 April 2014. Using the High-End Health Market for Regional Integration in Africa. Accessed 18 May 2021. Available online: https://www.howwemadeitinafrica.com/usingthe-high-end-health-market-for-regional-integration-inafrica/38019/

50. Prakash M, Tyagi N, Devrath R. A study of the Problems and Challenges Faced by Medical Tourists Visiting India 2011; Indian Institute of Tourism and Travel Management: Delhi, Indian, 2011.

51. Africa Renewal Dec 2016. Healthcare: from commitments to action. Accessed 18 May 2021. Available online: https:// www.un.org/africarenewal/magazine/december-2016march-2017/health-care-commitments-action

52. Schellekens OP, Lindner ME, Lange JMA, et al. A new paradigm for increased access to healthcare in Africa. Oct 2007. Accessed 18 May 2021. Available online: https:// www.pharmaccess.org/wp-content/uploads/2016/12/ A-new-paradigm-for-increased-access-to-healthcare-inAfrica_OS.pdf

53. Taylor A, Escobar E, Udayakumar K. Expanding Access to Low-Cost, High-Quality Tertiary Care: Spreading the Narayana Health Model Beyond India. Frugal innovations in health care delivery November 2017. Accessed 18 May 2021. Available online: https://collections.nlm.nih.gov/ master/borndig/101718851/taylor_expanding_lowcost_ highquality_model_narayana_cs.pdf

54. Duru F. Fuwai Hospital, Beijing, China: The World's Largest Cardiovascular Science Centre with more than 1200 beds. Eur Heart J 2018;39:428-9. 
55. Ma S, Sood N. Editors. A Comparison of the Health Systems in China and India. 2008. Publishers RAND Corporation, Santa Monica, CA. USA; Accessed 18 May 2021. Available online: https://www.rand.org/content/ dam/rand/pubs/occasional_papers/2008/RAND_

doi: 10.21037/asj-21-34

Cite this article as: Manuel V, Miana LA, Edwin F. Narrative review in pediatric and congenital heart surgery in sub-Saharan Africa: challenges and opportunities in a new era. AME Surg J 2021;1:26.
OP2 12.pdf

56. DE Oliveira AJM, Fresta M. Impact of International Training of Medical Specialists for underdeveloped Countries: Brazil- Angola experience. J Adv Med Educ Prof 2020;8:50-2. 